\title{
Selective induction of apoptosis by HMG-CoA reductase inhibitors in hepatoma cells and dependence on p53 expression
}

\author{
JANINE KAH $^{1}$, ANDREA WÜSTENBERG ${ }^{1}$, AMELIE DOROTHEA KELLER ${ }^{1}$, HÜSEYIN SIRMA ${ }^{2}$, \\ ROBERTA MONTALBANO ${ }^{3}$, MATTHIAS OCKER $^{3}$, TASSILO VOLZ $^{4}$, \\ MAURA DANDRI $^{4}$, GISA TIEGS ${ }^{1}$ and GABRIELE SASS ${ }^{1}$ \\ ${ }^{1}$ Institute of Experimental Immunology and Hepatology, University Medical Center Hamburg-Eppendorf, Hamburg; \\ ${ }^{2}$ Institute of Pathology, University Medical Center Hamburg-Eppendorf, Hamburg; ${ }^{3}$ Institute for Surgical Research, \\ Philipps University Marburg, Marburg; ${ }^{4}$ Department of Medicine I, University \\ Medical Center Hamburg-Eppendorf, Hamburg, Germany
}

Received March 19, 2012; Accepted April 30, 2012

DOI: 10.3892/or.2012.1860

\begin{abstract}
HMG-CoA-reductase inhibitors (statins) are widely used drugs to interfere with cholesterol biosynthesis. Besides this usage, evidence is increasing that statins might also be useful in therapy of viral infections or cancer. We investigated the effects of fluva-, simva-, atorva-, rosuva- and lovastatin on the viability of primary mouse and human hepatocytes as well as mouse (Hepa1-6) and human (Huh7, HepG2) hepatoma cell lines. Our results show selective cytotoxic effects of fluva-, simva- and lovastatin on hepatoma cells in comparison to primary hepatocytes. Using human hepatoma cells we found significant reduction of cell viability and induction of apoptosis in HepG2 cells, while statins did not affect Huh7 cells at concentrations not toxic for primary hepatocytes. Stable knockdown of endogenous $\mathrm{p} 53$, which is overexpressed in Huh7 cells, was able to restore susceptibility of Huh7 cells towards statin-induced toxicity. The anti-tumor effect of statins did not depend on a lack of cholesterol production, but was restored by supplementation of mevalonate or geranylgeranyl pyrophosphate, prerequisites for prenylation of small $\mathrm{G}$ proteins. In conclusion, statins display a selective apoptotic effect on human hepatoma cells, with fluva-, simva- and lovastatin being both, most selective for tumor cells and most effective in inducing tumor cell apoptosis. Additionally, our
\end{abstract}

Correspondence to: Dr Gabriele Sass, Institute of Experimental Immunology and Hepatology, University Medical Center HamburgEppendorf, Martinistr. 52, D-20246 Hamburg, Germany

E-mail: g.sass@uke.de

Abbreviations: HCC, hepatocellular carcinoma; LDLR, LDL receptor; GGPP, geranyl-geranyl-pyrophosphate; FLV, fluvastatin; SMV, simvastatin; ROV, rosuvastatin; ATV, atorvastatin; LOV, lovastatin; MVLT, mevalonate; PHhum, primary human hepatocytes; PCNA, proliferating cell nuclear antigen

Key words: statin, apoptosis, targeted therapy, p53, proliferation results implicate that anti-tumor activity of statins requires cell proliferation and is reduced by p53 overexpression.

\section{Introduction}

Statins are widely used drugs in therapy of hypercholesterinemia. They competitively inhibit HMG-CoA-reductase, a key enzyme in cholesterol biosynthesis, and additionally reduce blood LDL levels by inducing expression of LDL receptors (LDLR). Statins have been described to support anti-viral therapy (1-3) and to interfere with tumor growth in patients (4-6). Statistical correlation of statin use and cancer incidence revealed protection at least from stomach and liver cancer, as well as from lymphoma (7).

Although the multi-kinase-inhibitor Sorafenib has been shown to exert anti-tumor activity and to prolong patient survival $(8,9)$, hepatocellular carcinoma (HCC) still is among the most prevalent malignancies worldwide (10). Statins might be able to broaden the spectrum of drugs useful in therapy of HCC. In fact, various statins have been tested for their potential to interfere with hepatoma cell growth alone (11-14) or in combination $(15,16)$. On the other hand, when applied at high doses or to patients with impaired liver functions statins have severe side effects, e.g., myopathy or liver toxicity $(17,18)$. Therefore, it would be favourable to use statins in HCC therapy which do not further affect functional primary hepatocytes. We investigated selectivity of anti-tumor effects for 5 commonly prescribed statins using human and mouse hepatoma cell lines in comparison to primary hepatocytes. Our results in the human and in the mouse system show a more selective effect of fluva-, simva- and lovastatin on hepatoma cells compared to primary hepatocytes. Sensitivity of hepatoma cell lines towards statin incubation was dependent on cellular proliferation and correlated to the expression of p53. The p53 over-expressing human hepatoma cell line Huh7 could be sensitized towards statin-induced apoptosis by a knockdown of p53. Apoptosis induction by statins in tumor cells was found to be based on inhibition of prenylation, since restoration of geranyl-geranylation reverted statin cytotoxicity in vitro. These results further point to beneficial effects of statin treatment of HCC patients, 
but also implicate the use of selected statins and that anti-tumor effects might depend on individual patient tumor conditions, e.g., p53 expression status of the tumor.

\section{Materials and methods}

Reagents. HMG-CoA-reductase inhibitors fluva- and simvastatin (Cayman Chemical, Ann Arbor, MI, USA), atorvastatin (Sortis, Pfizer Pharma $\mathrm{GmbH}$ ), rosuvastatin (Crestor, Astra Zeneca) and lovastatin (Tocris Bioscience; Bristol, UK) were dissolved in DMSO. As a vehicle control, DMSO was dissolved to the concentrations used on statin incubated cells and measured in parallel. Mevalonate (MVLT), geranyl-geranyl-pyrophosphate (GGPP), and cholesterol were purchased from Sigma-Aldrich Chemie GmbH; Steinheim, Germany. Final concentrations (as indicated in the figures and figure legends) were obtained by dilution in medium.

Cell culture. The human hepatoma cell lines Huh7 (19) and HepG2 (20) were cultured in DMEM containing 10\% fetal calf serum (FCS) (both from Invitrogen $\mathrm{GmbH}$, Karlsruhe, Germany) and $1 \%$ penicillin/streptomycin (Biochrom AG Seromed, Berlin, Germany). The mouse hepatoma cell line Hepal-6 (21) was maintained in RPMI-1640 medium (10\% FCS; $1 \%$ penicillin/ streptomycin). For experimental procedures cells were seeded into 24- or 96-well plates and allowed to adhere overnight.

Isolation of primary hepatocytes. Mouse primary hepatocytes $(\mathrm{C} 57 \mathrm{Bl} / 6)$ were isolated by a modification of the two-step collagenase perfusion method of Seglen (22) and cultured in William's E+GlutaMAXTM-I medium, supplemented with $10 \%$ FCS, $1 \%$ L-glutamine, 2\% 4-(2-hydroxyethyl)-1-piperazineethanesulfonic acid (HEPES), $1 \%$ sodium pyruvate (all from Invitrogen $\mathrm{GmbH}$ ) and $1 \%$ penicillin/streptomycin (Biochrom AG Seromed). Primary human hepatocytes were isolated as described previously (23).

Stable knockdown. ShRNA expressing vectors were based on the lentiviral pLKO.1 construct (RNAi Consortium vector collection (24) and purchased from Sigma Aldrich $\mathrm{GmbH}$. Target sequences for shRNA were TGG GTC CTT ACA CTC AGC TTT CT for p53 (shp53) and TTA TCG CGC ATA TCA CGC G for E. coli DNA polymerase as a control gene (shneg). Transduced cells were selected using $2 \mu \mathrm{g} / \mathrm{ml}$ puromycin (Carl Roth $\mathrm{GmbH}+\mathrm{Co}$. KG; Karlsruhe, Germany).

Analysis of cell viability, proliferation and apoptosis. Cell viability was measured by using (3-4, 5-dimethylthiazol2-yl)-2,5-diphenyltetrazolium bromide (MTT; Sigma Aldrich $\mathrm{GmbH}$ ) according to the manufacturer's instructions. Cellular proliferation and viability was measured by the xCELLigence real-time cell analyzing system (Roche Molecular Diagnostics, Mannheim, Germany). Briefly, 10,000 cells were seeded per well of a 96-well E-plate and viability was measured continuously as impedance and expressed as an arbitrary unit named cell index. Data were normalized to the time-point of seeding and represent means of triplicates as described previously (25). Dead cells were visualized by trypan blue staining and cell counting using a Neubauer chamber (Carl Roth GmbH + Co. $\mathrm{KG})$. Total cell numbers as well as the percentages of dead cells
Table I. Oligonucleotide sequences for real-time RT-PCR.

\begin{tabular}{ll}
\hline Oligonucleotide & Sequence 5'-3' \\
\hline 5'GAPDHhum & 5'-TGA TGA CAT CAA GAA GGT GG-3' \\
3'GAPDHhum & 5'-CGA CCA CTT TGT CAA GCT C-3' \\
5'mATPsynthase & 5'-GCC CAC TTC TTA CCA CAA GG-3' \\
3'mATPsynthase & 5'-GCG ACA GCG ATT TCT AGG AT-3' \\
5'PCNAhum & 5'-GGC GTG AAC CTC ACC AGT AT-3' \\
3'PCNAhum & 5'-TCT CGG CAT ATA CGT GCA AA-3' \\
\hline
\end{tabular}

were determined at 72-h incubation. To quantify apoptosis, activation of caspase 3 was measured using the colorimetric assay (Sigma Aldrich $\mathrm{GmbH}$ ) according to the manufacturer's instructions.

Western blot analyses. Protein $(25 \mu \mathrm{g})$ was fractionated by $12 \%$ SDS-polyacrylamide gel electrophoresis and blotted onto nitrocellulose membranes. Western blot analyses were developed using an enhanced chemiluminescence system (Amersham, GE Healthcare Europe GmbH, Munich, Germany) according to the manufacturer's instructions. Semi-quantitative evaluation was performed using the VersaDoc Imaging System (Bio-Rad Laboratories $\mathrm{GmbH}$, Munich, Germany). Antibodies: rabbit anti-p53 (1:1000; Santa Cruz Biotechnology, Inc., Santa Cruz, CA, USA) and mouse anti-GAPDH (1:5000; HyTest Ltd., Turku, Finland).

Detection of $m R N A$ by $R T-P C R$. To verify altered gene expression RNA was transcribed into cDNA using the Verso $^{\mathrm{TM}}$ cDNA kit (Thermo Fisher Scientific, Waltham, MA, USA). Oligonucleotides for subsequent PCR-reactions were obtained from Metabion International AG (Martinsried, Germany) and are summarized in Table I. Real-time RT-PCR was performed using the CFXTM real-time system (Bio-Rad Laboratories $\mathrm{GmbH}$ ) and reagents from ABgene ${ }^{\circledR}$ (Epsom, UK). To confirm amplification specificity, PCR products were subjected to melting curve analysis and gel electrophoresis.

Statistical analysis. The results were analyzed using Student's t-test, if two groups were compared and Dunnett's test if more groups were tested against a control group. If variances were inhomogeneous in Student's t-test, the results were analyzed using the Welsh test. The data in this study are expressed as a mean \pm SEM. $\mathrm{P} \leq 0.05$ was considered significant.

\section{Results}

Fluvastatin, simvastatin and lovastatin dose-dependently and selectively reduce viability of mouse hepatoma cells. The use of statins has been shown to affect hepatic tumor growth in patients (6), but also bears the risk of severe side effects when over-dosed or applied to patients with e.g., impaired liver function $(17,18)$. To investigate which statin might have the highest efficacy in HCC therapy and to predict the probability of side effects we first compared viability of freshly isolated primary mouse hepatocytes $(\mathrm{PH})$ in the presence of increasing concen- 
A

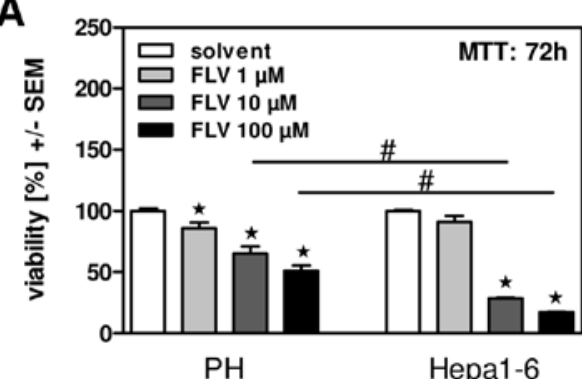

C

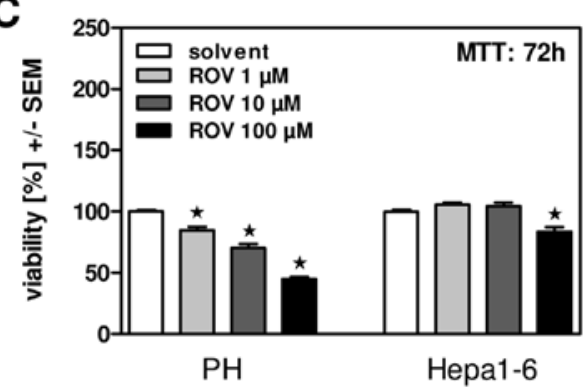

E

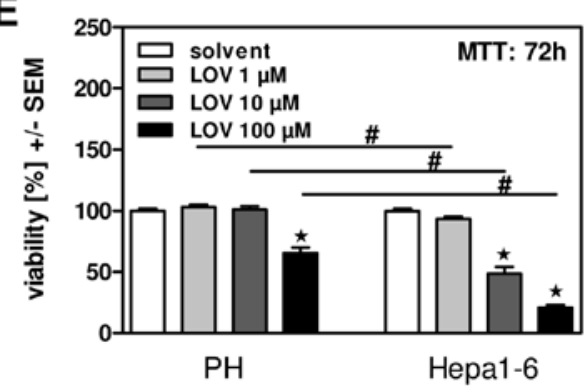

B

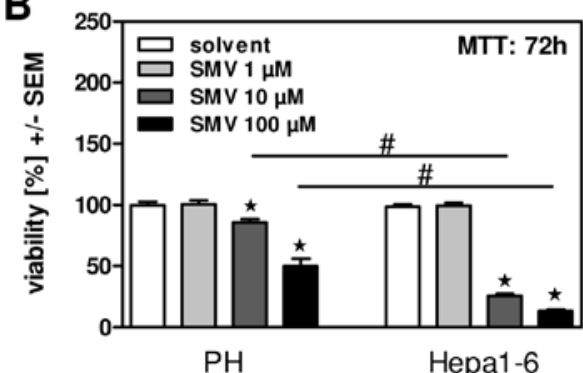

D

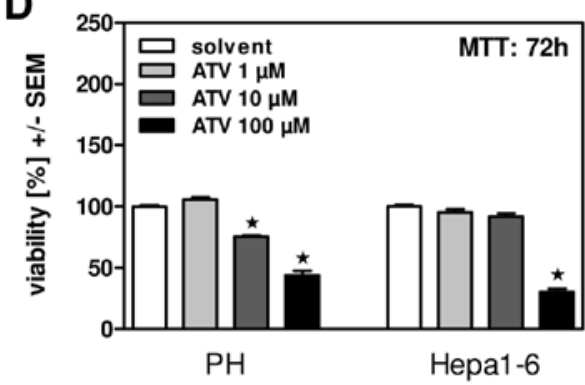

F

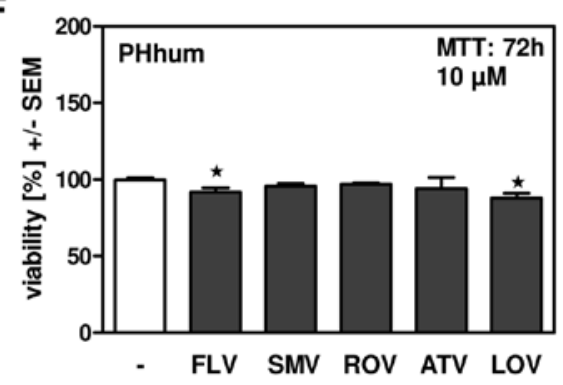

Figure 1. FLV, SMV and LOV dose-dependently and selectively reduce viability of mouse hepatoma cells. Primary mouse hepatocytes (PH) or mouse hepatoma cells (Hepa1-6) were incubated in the presence of fluvastatin (FLV; A), simvastatin (SMV; B), rosuvastatin (ROV; C), atorvastatin (ATV; D), or lovastatin (LOV; E) at 1,10 or $100 \mu \mathrm{M}$ for $72 \mathrm{~h}$. Cell viability was measured by MTT assay. "P $\leq 0.05$ for statin vs. solvent incubated cells; "P $\leq 0.05$ for statin incubated PH vs. Hepa1-6 cells. (F) Primary human hepatocytes (PHhum) were incubated in the presence of FLV, SMV, ROV, ATV, or LOV at $10 \mu \mathrm{M}$ for $72 \mathrm{~h}$. Cell viability was measured by MTT assay. ${ }^{*} \mathrm{P} \leq 0.05$ for statin vs. solvent incubated cells.

trations of statins to mouse hepatoma cells (Hepa1-6) in vitro. Using fluva- (FLV), simva- (SMV), rosuva- (ROV), atorva(ATV), as well as lovastatin (LOV) we found that within $72 \mathrm{~h}$ of incubation, FLV (Fig. 1A), SMV (Fig. 1B) and LOV (Fig. 1E) significantly reduced viability of hepatoma cells in comparison to PH, while ROV (Fig. 1C), and ATV (Fig. 1D) did not. At a concentration of $10 \mu \mathrm{M}$ FLV, SMV and LOV effects on mouse hepatoma cells were significantly more pronounced than effects on primary mouse hepatocytes. We also chose this concentration to compare the impact of all 5 statins on viability of primary human hepatocytes (PHhum). Our results show that PHhum in general were much more resistant towards statin incubation than mouse hepatocytes, with only mild toxic effects being observed for FLV and LOV (Fig. 1F).

FLV, SMV and LOV efficiently reduce viability of Hep G2 but not Huh7 human hepatoma cells. Incubating the human hepatoma cell lines Huh7 and HepG2 in the presence of $10 \mu \mathrm{M}$ of statins we found that FLV and LOV showed mild toxic effect on Huh7 cells, while none of the other statins reduced viability of this cell line (Fig. 2A). In contrast, all statins significantly interfered with viability of HepG2 cells (Fig. 2A). Again, most pronounced effects were observed for FLV, SMV and LOV, while effects of
ATV were intermediate and ROV had only moderate effects on viability of HepG2 cells (Fig. 2A). We also measured apoptosis induction by FLV, SMV and LOV in Huh7 and HepG2 cells and found that these statins induced apoptosis in HepG2, but not in Huh7 human hepatoma cells (Fig. 2B). These results indicate that statins in principle are able to induce apoptosis in tumor cells. Measuring real-time proliferation of HepG2 and Huh7 cells we found that HepG2 cells were proliferating much faster than Huh7 cells (Fig. 2C). This finding was in line with results from real-time RT-PCR, where expression of proliferating cell nuclear antigen (PCNA) was found to be significantly higher in HepG2 cells (Fig. 2D).

Protection of Huh7 cells against statin induced cytotoxicity seems to depend on over-expression of p53. As shown in Fig. 2A and B Huh7 human hepatoma cells were much more resistant against statin incubation than HepG2 cells. One fundamental difference between these cell lines is their content of p53 tumor suppressor protein. While HepG2 cells express normal amounts of p53, Huh7 cells accumulate high amounts of p53 (26). We confirmed this observation in our cell lines by Western blot analysis (Fig. 3A). Based on the hypothesis that high amounts of p53 would interfere with cell proliferation, which might be 
A

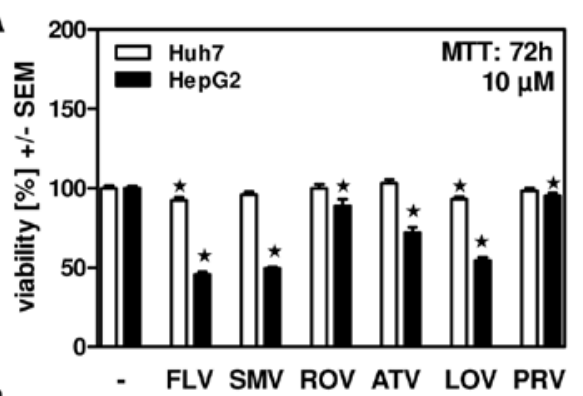

B

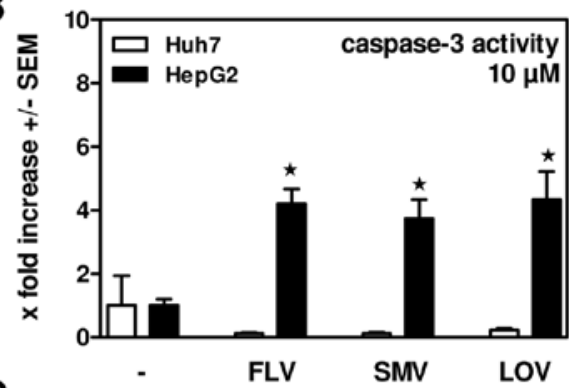

C
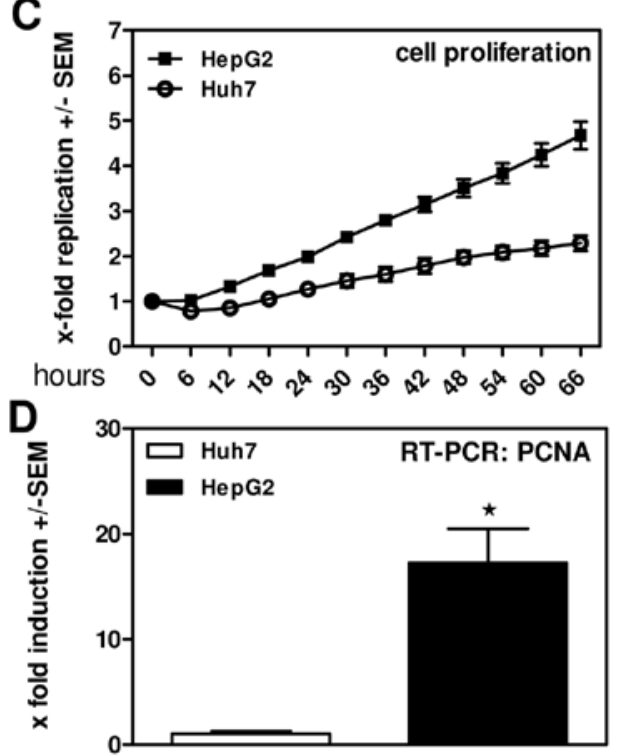

Figure 2. FLV, SMV and LOV efficiently and selectively reduce viability of human hepatoma cell lines. (A) Human hepatoma cells (Huh7; HepG2) were incubated in the presence of fluvastatin (FLV), simvastatin (SMV), rosuvastatin (ROV), atorvastatin (ATV), or lovastatin (LOV) at $10 \mu \mathrm{M}$ for $72 \mathrm{~h}$. Cell viability was measured by MTT assay. ${ }^{*} \mathrm{P} \leq 0.05$ for statin vs. solvent incubated cells. (B) Apoptosis induction was measured in Huh7 and HepG2 cells after $48 \mathrm{~h}$ statin incubation by caspase- 3 activity assay. ${ }^{*} \mathrm{P} \leq 0.05$ for statin vs. solven incubated cells. (C) Proliferation of Huh7 and HepG2 cells was measured continuously over a period of $66 \mathrm{~h}$ using the impedance-based xCELLigence real-time cell analyzing system. Results are expressed as mean cell index normalized to the time-point of seeding to 96-well E-plates. (D Expression of proliferating cell nuclear antigen (PCNA) was measured in Huh7 and HepG2 human hepatoma cells by real-time RT-PCR. "P $\leq 0.05$.

the reason for decreased sensitivity of Huh7 cells towards statin-induced cytotoxicity, we generated Huh7 cells with a stable knockdown of p53 (shp53). Western blot analysis (Fig. $3 \mathrm{~B})$ revealed a p53 knockdown of $\sim 50 \%$ on protein level compared to cells expressing shRNA directed against $E$. coli polymerase (shneg) as a control for unspecific knockdown. Incubation of both cell lines in the presence of FLV, SMV or LOV revealed significantly reduced cellular viability (Fig. 3C) and increased apoptosis induction (Fig. 3D) by statins in
A
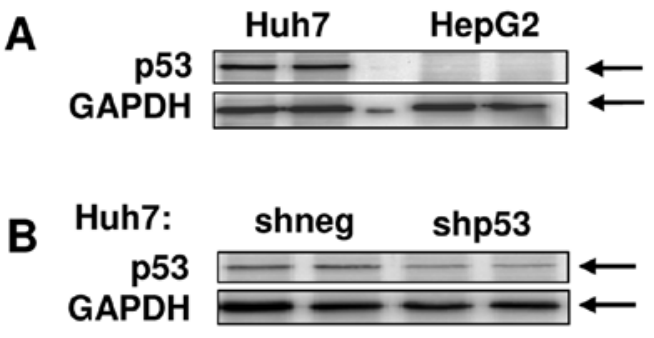

C

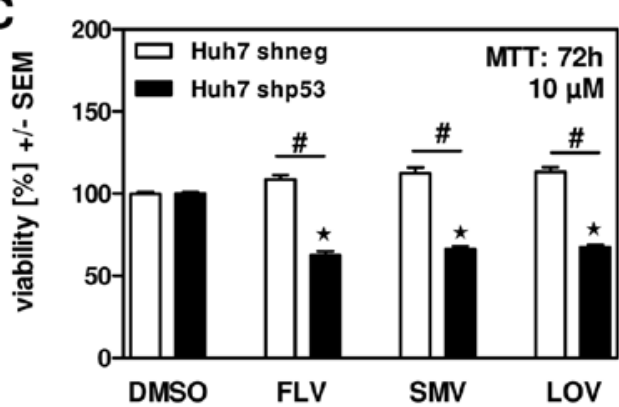

D

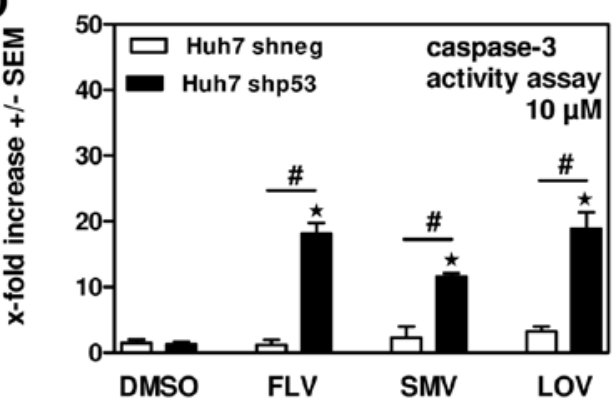

E

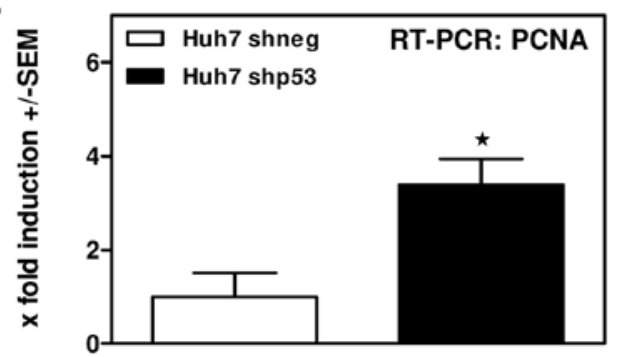

Figure 3. p53 expression of human hepatoma cell lines correlates to their susceptibility towards statins. (A) p53 protein expression was measured in human hepatoma cells (Huh7; HepG2) by Western blotting. (B) p53 protein expression was measured by Western blotting in Huh7 cells with stable knockdown of p53 (shp53) or Huh7 cells expressing control shRNA directed against E.coli polymerase (shneg). Huh7 shneg or Huh7 shp53 cells were incubated in the presence of $10 \mu \mathrm{M}$ fluvastatin (FLV), simvastatin (SMV) or lovastatin (LOV) for $72 \mathrm{~h}$. Cell viability was measured by MTT assay (C), apoptosis induction was measured by caspase- 3 activity assay (D). Expression of proliferating cell nuclear antigen (PCNA) was measured by real-time RT-PCR. "P $\leq 0.05$ for Huh7 shneg vs. Huh7 shp53 cells.

the presence of the p53 knockdown, providing evidence that p53 might contribute to resistance against anti-tumor effects of statins. Our hypothesis was further supported by the finding that p53 knockdown increased expression of PCNA as a marker for proliferation activity (Fig. 3E).

Statins induce tumor cell apoptosis by interfering with geranylgeranylation. To further characterize apoptosis induction by statins in hepatoma cells we investigated if reduced biosynthesis 
A

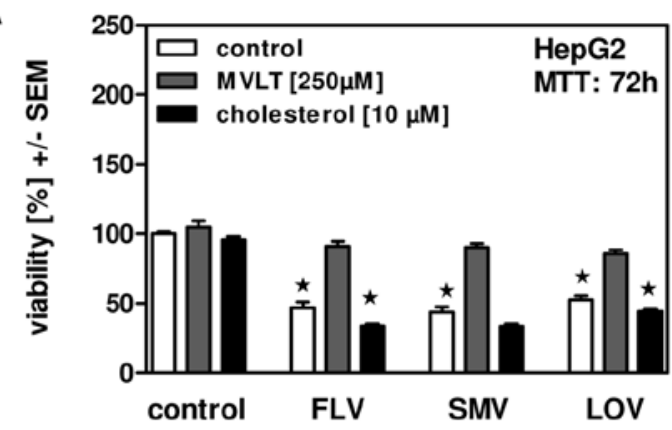

C

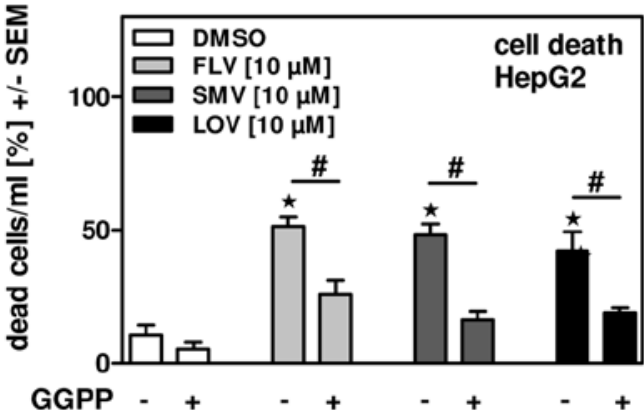

B
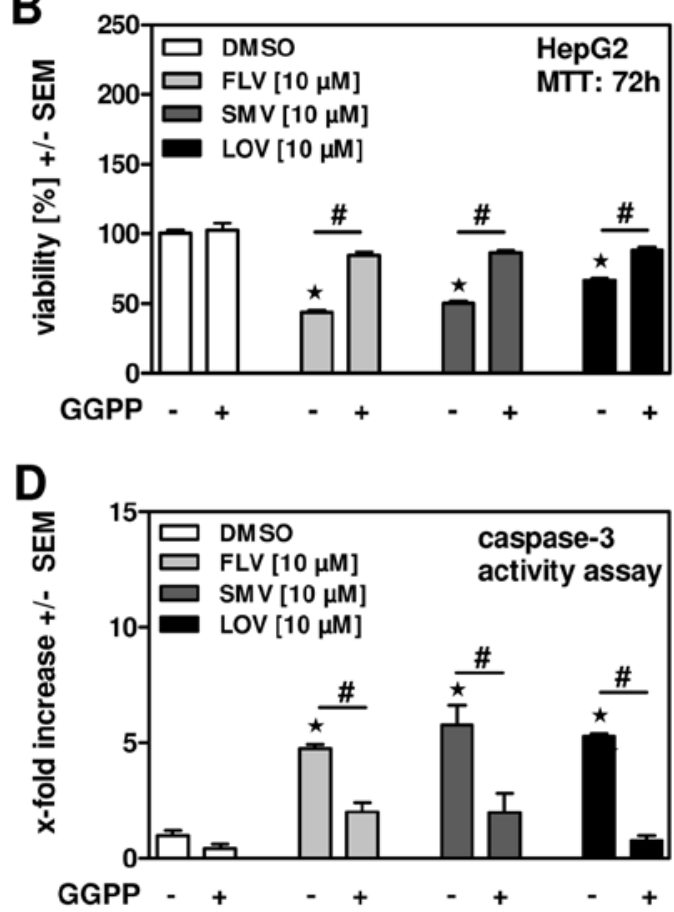

Figure 4. Statins reduce viability and induce apoptosis of tumor cells by interfering with geranyl-geranylation. (A) HepG2 human hepatoma cells were incubated in the presence of $10 \mu \mathrm{M}$ fluvastatin (FLV), simvastatin (SMV) or lovastatin (LOV) with or without co-incubation with cholesterol (10 $\mu \mathrm{M}$ ) or mevalonate (MVLT) $(250 \mu \mathrm{M})$ for $72 \mathrm{~h}$. Cell viability was measured by MTT assay. ${ }^{*} \mathrm{P} \leq 0.05$ for statin vs. solvent incubated cells. HepG2 cells were incubated in the presence of statins with or without co-incubation with geranyl-geranyl-pyrophosphate (GGPP) $(10 \mu \mathrm{M})$. Cell viability was measured by MTT assay (B). The percentage of dead cells in culture was measured by trypan blue staining and cell counting (C). Apoptosis induction was measured by caspase-3 activity assay (D). $\mathrm{P} \leq 0.05$ for statin incubated vs. solvent incubated cells. "P $\leq 0.05$ for statin incubated cells with or without co-incubation with GGPP.

of cholesterol itself or an intermediate step in the cholesterol biosynthesis pathway might be responsible. Therefore, HepG2 cells were incubated in the presence of FLV, SMV or LOV with or without cholesterol or mevalonate (MVLT) supplementation. Our results show that cholesterol was not able to restore cell viability (Fig. 4A), while MVLT did, indicating that inhibition of the cholesterol synthesis pathway rather than a lack of cholesterol seems to be responsible for induction of hepatoma cell death by statins. By interfering with the cholesterol biosynthesis pathway statins deprive cells of signaling molecules, e.g., geranyl-geranyl-pyrophosphate (GGPP), necessary for prenylation of small G-proteins and subsequent maintenance of cellular integrity. This might be especially important for fast proliferating tumor cells. To investigate this hypothesis we incubated HepG2 cells in parallel with statins and GGPP and found a partially restoration of cell viability (Fig. 4B) and inhibition of cell death, as measured by counting dead cells as a percentage of whole cell numbers (Fig. 4C) or apoptosis induction (Fig. 4D). The same effects were observed when incubating mouse hepatoma cells (Hepa1-6) in the presence of statins and GGPP (data not shown), indicating a generalized mechanism. In conclusion, our results implicate that FLV, SMV and most prominently LOV induce apoptosis in hepatoma cell lines by interfering with cellular integrity.

\section{Discussion}

Besides their role in regulation of endogenous cholesterol synthesis and lipoprotein metabolism statins have been shown to exert pleiotopic effects, e.g., on pancreatic or prostate cancer $(4,5)$. Moreover, it has been observed that diabetes patients with additional statin therapy have a lower risk to develop HCC (6). It has been described that e.g., FLV and SMV induce apoptosis and cell cycle arrest in hepatoma cell lines $(11,12)$, ATV blocks both Myc phosphorylation and activation, suppressing tumor initiation and growth in vivo (13) and that SMV modifies the expression of cell adhesion molecules leading to reduced tumor cell growth and invasion (14). Moreover, statins showed synergistic anti-tumor effects with e.g., the COX-2 inhibitor celecoxib (15) or the PKC beta inhibitor enzastaurin (16).

In the present study, we compared anti-tumor effects of FLV, SMV, ATV, ROV and LOV on human and mouse hepatoma cell lines to effects on primary human or mouse hepatocytes. Our general observation was that anti-tumor effects of FLV, SMV and LOV on hepatoma cell lines were significantly more pronounced compared to effects on primary hepatocytes, which implicates that these statins might be especially useful and better tolerated in therapy of HCC patients.

Our results also show that there are profound differences in the susceptibility of human hepatoma cell lines towards statin treatment, pointing to the fact that not every HCC patient might benefit from statin therapy. It seems that anti-tumor effects of statins are tightly linked to the proliferative capacity of cells. We found that slow proliferating Huh7 cells, like the in vitro almost quiescent primary human hepatocytes, were significantly less affected by statins than e.g., the fast proliferating human hepatoma cell line HepG2. Along with inhibition of cholesterol biosynthesis statins also deprive hepatocytes 
of intermediate products, e.g., mevalonate or the isoprenoids geranyl-geranyl-pyrophosphate (GGPP) and farnesyl-pyrophosphate (FPP), which are necessary for post-translational modifications and activation of cellular proteins, e.g., small G-proteins of the Ras superfamily (27). These proteins are regulators of important biological processes, including cell survival and cell growth, organization of the cytoskeleton and cell motility, intracellular vesicle formation and trafficking as well as nucleo-cytoplasmic transport (28). Fast growing tumor cells have a higher consumption of those intermediate products for reproduction of the cytoskeleton due to increased cell cycle activity and permanent cell division. Inline with our observations, statins have also been shown to affect prostate cancer cells by inhibition of prenylation (29). While these observations indicate that cancer therapy with certain statins might preferentially target fast proliferating tumor cells, these findings also implicate that necessary regenerative processes within the liver might be subject to statin toxicity. Therefore, only statins with high selectivity for tumor cells, i.e., FLV, SMV or LOV might be useful in supplementation of HCC treatment.

A reason for reduced proliferation and susceptibility of Huh7 cells towards statins might be their enhanced content of the tumor suppressor protein p53 compared to e.g., HepG2 cells. Huh7 hepatoma cells accumulate high amounts of p53 (26) and show reduced cellular proliferation. In fact we found that the ability of statins to induce apoptosis in hepatoma cell lines directly correlated with the levels of p53. Huh7 cells did not respond to statin incubation at concentrations achievable in patients (the maximum daily dose of FLV for a patient would correspond to $\sim 30 \mu \mathrm{M}$ in vitro), while a knockdown of p53 by $\sim 50 \%$ increased statin effects significantly. This implicates that only HCC with a particularly high expression or availability of p53 might be protected against statin toxicity, which is a rare event and supports the potential use of statins in HCC therapy. Nevertheless, the 553 pathway seems to play a role in the mechanism of apoptosis induction by statins.

G1/S cell cycle arrest in human HCC cell lines has been proposed as a mechanism for statins-induced apoptosis (30). Regarding the balance between tolerable statin concentrations for primary cells and a certain necessity for cell proliferation to achieve statin toxicity it has to be evaluated if repeated cycles rather than high doses of statin treatment might have a more beneficial impact on tumor regression rates. It also has to be evaluated if the combination of statins with anti-proliferative tumor therapy is recommendable.

\section{Acknowledgements}

This work was supported by the Deutsche Forschungsgemeinschaft (DFG): grant SA 1378/3-1 to G.S. and M.D.; SFB 841 graduate school 'Inflammation \& Regeneration' to G.T. The expert technical assistance of Elena Tasika is gratefully acknowledged.

\section{References}

1. Bader T and Korba B: Simvastatin potentiates the anti-hepatitis B virus activity of FDA-approved nucleoside analogue inhibitors in vitro. Antiviral Res 86: 241-245, 2010.
2. Delang L, Paeshuyse J, Vliegen I, Leyssen P, Obeid S, Durantel D, Zoulim F, Op de Beeck A and Neyts J: Statins potentiate the in vitro anti-hepatitis $C$ virus activity of selective hepatitis $C$ virus inhibitors and delay or prevent resistance development. Hepatology 50: 6-16, 2009.

3. Ikeda M, Abe K, Yamada M, Dansako H, Naka K and Kato N: Different anti-HCV profiles of statins and their potential for combination therapy with interferon. Hepatology 44: 117-125, 2006.

4. Murtola TJ, Tammela TL, Määttänen L, Huhtala H, Platz EA, Ala-Opas M, Stenman UH and Auvinen A: Prostate cancer and PSA among statin users in the finnish prostate cancer screening trial. Int J Cancer 127: 1650-1659, 2010.

5. Ishikawa S, Nagai Y, Masuda T, Koga Y, Nakamura T, Imamura Y, Takamori H, Hirota M, Funakosi A, Fukushima M and Baba H: The role of oxysterol binding protein-related protein 5 in pancreatic cancer. Cancer Sci 101: 898-905, 2010.

6. El-Serag HB, Johnson ML, Hachem C and Morgana RO: Statins are associated with a reduced risk of hepatocellular carcinoma in a large cohort of patients with diabetes. Gastroenterology 136: 1601-1608, 2009.

7. Kuoppala J, Lamminpää A and Pukkala E: Statins and cancer: a systematic review and meta-analysis (review). Eur J Cancer 44: 2122-2132, 2008

8. Llovet JM, Ricci S, Mazzaferro V, Hilgard P, Gane E, Blanc JF, de Oliveira AC, Santoro A, Raoul JL, Forner A, Schwartz M, Porta C, Zeuzem S, Bolondi L, Greten TF, Galle PR, Seitz JF, Borbath I, Häussinger D, Giannaris T, Shan M, Moscovici M, Voliotis D and Bruix J; SHARP Investigators Study Group: Sorafenib in advanced hepatocellular carcinoma. N Engl J Med 359: 378-390, 2008.

9. Cheng AL, Kang YK, Chen Z, Tsao CJ, Qin S, Kim JS, Luo R, Feng J, Ye S, Yang TS, Xu J, Sun Y, Liang H, Liu J, Wang J, Tak WY, Pan H, Burock K, Zou J, Voliotis D and Guan Z: Efficacy and safety of sorafenib in patients in the Asia-Pacific region with advanced hepatocellular carcinoma: a phase III randomised, doubleblind, placebo-controlled trial. Lancet Oncol 10: 25-34, 2009.

10. Parkin DM, Bray F, Ferlay J and Pisani P: Estimating the world cancer burden: Globocan 2000. Int J Cancer 94: 153-156, 2001.

11. Relja B, Meder F, Wilhelm K, Henrich D, Marzi I and Lehnert M: Simvastatin inhibits cell growth and induces apoptosis and G0/ G1 cell cycle arrest in hepatic cancer cells. Int J Mol Med 26: 735-741, 2010.

12. Zhang W, Wu J, Zhou L, Xie HY and Zheng SS: Fluvastatin, a lipophilic statin, induces apoptosis in human hepatocellular carcinoma cells through mitochondria-operated pathway. Indian J Exp Biol 48: 1167-1174, 2010

13. Cao Z, Fan-Minogue H, Bellovin DI, Yevtodiyenko A, Arzeno J, Yang Q, Gambhir SS and Felsher DW: MYC phosphorylation, activation, and tumorigenic potential in hepatocellular carcinoma are regulated by HMG-CoA reductase. Cancer Res 71: 2286-2297, 2011.

14. Relja B, Meder F, Wang M, Blaheta R, Henrich D, Marzi I and Lehnert M: Simvastatin modulates the adhesion and growth of hepatocellular carcinoma cells via decrease of integrin expression and ROCK. Int J Oncol 38: 879-885, 2011.

15. Gao J, Jia WD, Li JS, Wang W, Xu GL, Ma JL, Ge YS, Yu JH, Ren WH, Liu WB and Zhang CH: Combined inhibitory effects of celecoxib and fluvastatin on the growth of human hepatocellular carcinoma xenografts in nude mice. J Int Med Res 38: 1413-1427, 2010.

16. Kim W, Yoon JH, Kim JR, Jang IJ, Bang YJ, Kim YJ and Lee HS: Synergistic anti-tumor efficacy of lovastatin and protein kinase C-beta inhibitor in hepatocellular carcinoma. Cancer Chemother Pharmacol 64: 497-507, 2009.

17. Neuvonen PJ: Drug interactions with HMG-CoA reductase inhibitors (statins): the importance of CYP enzymes, transporters and pharmacogenetics (review). Curr Opin Investig Drugs 11: 323-332, 2010.

18. Brown WV: Safety of statins. Curr Opin Lipidol 19: 558-562, 2008.

19. Nakabayashi H, Taketa K, Yamane T, Miyazaki M, Miyano K and Sato J: Phenotypical stability of a human hepatoma cell line, HuH-7, in long-term culture with chemically defined medium. Gann 75: 151-158, 1984

20. Aden DP, Fogel A, Plotkin S, Damjanov I and Knowles BB Controlled synthesis of HBsAg in a differentiated human liver carcinoma-derived cell line. Nature 282: 615-616, 1979. 
21. Darlington GJ, Bernhard HP, Miller RA and Ruddle J: Expression of liver phenotypes in cultured mouse hepatoma cells. J Natl Cancer Inst 64: 809-819, 1980.

22. Seglen PO: Preparation of rat liver cells. 3. Enzymatic requirements for tissue dispersion. Exp Cell Res 82: 391-398, 1973

23. Dandri M, Burda MR, Török E, Pollok JM, Iwanska A, Sommer G, Rogiers X, Rogler CE, Gupta S, Will H, Greten $\mathrm{H}$ and Petersen J: Repopulation of mouse liver with human hepatocytes and in vivo infection with hepatitis B virus. Hepatology 33: 981-988, 2001.

24. Moffat J, Grueneberg DA, Yang X, Kim SY, Kloepfer AM, Hinkle G, Piqani B, Eisenhaure TM, Luo B, Grenier JK, Carpenter AE, Foo SY, Stewart SA, Stockwell BR, Hacohen N, Hahn WC, Lander ES, Sabatini DM and Root DE: A lentiviral RNAi library for human and mouse genes applied to an arrayed viral high-content screen. Cell 124: 1283-1298, 2006.

25. Gloesenkamp CR, Nitzsche B, Ocker M, Di Fazio P, Quint K, Hoffmann B, Scherübl H and Höpfner M: AKT inhibition by triciribine alone or as combination therapy for growth control of gastroenteropancreatic neuroendocrine tumors. Int J Oncol 40 876-888, 2012.
26. Bressac B, Galvin KM, Liang TJ, Isselbacher KJ, Wands JR and Ozturk M: Abnormal structure and expression of p53 gene in human hepatocellular carcinoma. Proc Natl Acad Sci USA 87: 1973-1977, 1990

27. Chan KKW, Oza AM and Siu LL: The statins as anticancer agents. Clin Cancer Res 9: 10-19, 2003.

28. Konstantinopoulos PA, Karamouzis MV and Papavassiliou AG: Post-translational modification and regulation of the RAS superfamily of GTPases as anticancer targets. Nat Rev Drug Discov 6: 541-555, 2007.

29. Roy M, Kung HJ and Ghosh PM: Statins and prostate cancer: role of cholesterol inhibition vs. prevention of small GTP-binding proteins. Am J Cancer Res 1: 542-561, 2011.

30. Sutter AP, Maaser K, Höpfner M, Huether A, Schuppan D and Scherübl H: Cell cycle arrest and apoptosis induction in hepatocellular carcinoma cells by HMG-CoA reductase inhibitors. Synergistic antiproliferative action with ligands of the peripheral benzodiazepine receptor. J Hepatol 43: 808-816, 2005. 